\title{
Treating early and treating well: the importance of restoring global functioning for the brains of schizophrenia patients
} Rene Kahn

\author{
Address: Department of Psychiatry, Rudolf Magnus Institute of Neuroscience, University Medical Center Utrecht, The Netherlands \\ from International Society on Brain and Behaviour: 3rd International Congress on Brain and Behaviour \\ Thessaloniki, Greece. 28 November - 2 December 2007 \\ Published: 17 April 2008 \\ Annals of General Psychiatry 2008, 7(Suppl I):S63 doi:I0.1186/1744-859X-7-SI-S63
}

This abstract is available from: http://www.annals-general-psychiatry.com/content/7/SI/S63

(c) 2008 Kahn; licensee BioMed Central Ltd.

Brain imaging studies have consistently demonstrated brain abnormalities in patients with schizophrenia. These changes are largely confined to decreases in gray matter volumes and enlargement of the lateral and third ventricles. To date schizophrenia has been considered to result from abnormalities in neurodevelopment, with brain changes to be static. However, schizophrenia has long been thought to be a progressive or a degenerative, not a developmental, disorder. Indeed, Kraepelin considered the progressive clinical deterioration to be the hallmark of the disorder, naming it dementia praecox to reflect this particular aspect. Lately, others have re-emphasised the importance of the decline in functioning in schizophrenia as a clue to its pathogenesis, suggesting that the brain abnormalities in schizophrenia could be expected to reflect this clinical progression. Indeed, we and others $[1,2]$ have reported brain abnormalities to increase over time in schizophrenia. Interestingly, not all patients show changes in brain volumes over time: we demonstrated that the changes are particularly pronounced in those patients with a poor prognosis in the first years of illness. Moreover progressive changes are most pronounced in the frontal and temporal areas as postulated by Kraepelin over a hundred years ago. Interestingly, white matter did not change over time. Finally, the progression in these frontal brain changes appeared to be attenuated by treatment with atypical, but not by typical antipsychotics. Thus, not only are brain changes progressive in schizophrenia, they are clinically relevant since they are related to outcome and my be reversed by some of the atypical antipsychotics. With the evidence pointing to a link between progressive disease and patient outcomes, questions such as whether these changes can be reversed with early pharmacological intervention and whether there is a point at which the brain changes become irreversible, become pertinent.

\section{References}

I. van Haren NE, Hulshoff Pol HE, Schnack HG, Cahn W, Mandi RC, Collins DL, Evans AC, Kahn RS: Focal Gray Matter Changes in Schizophrenia across the Course of the Illness: A 5-Year Follow-Up Study. Neuropsychopharmacology 2007, 32:2057-2066.

2. Cahn W, van Haren NE, Hulshoff Pol HE, Schnack HG, Caspers E, Laponder DA, Kahn RS: Brain volume changes in the first year of illness and 5-year outcome of schizophrenia. Br J Psychiatry 2006, 189:38I-382. 